\title{
An update on the UK government's plans for a national underground asset register
}

\author{
The UK government's Geospatial Commission is trying to improve the way industry and authorities \\ manage and share data about the UK's buried infrastructure assets. Neil Brammall and Holger \\ Kessler provide an update on their plans to build the National Underground Asset Register.
}

People installing, maintaining and repairing underground utilities and other infrastructure do not have an easy job. Aside from the physical hazards, siloed data make it difficult to get information on what lies underground before starting to dig.

The result is a tedious process of contacting numerous asset owners and waiting for responses to get a full picture before being able to start. In emergencies, digging sometimes has to get underway with very little prior knowledge of what will be encountered, increasing the likelihood of accidents.

The economic costs of underground asset strikes and consequent delays to projects in the UK alone are estimated to be $f 1.2$ billion a year. The government has therefore set up the Geospatial Commission to solve the problem of getting access to underground asset data, particularly where there is evidence of economic, social or environmental benefits.

\section{Pilot projects}

After establishing a small research team in 2018 (Kessler, 2019), the Commission started to study similar initiatives, including the 'Vault' system in Scotland (SRWC, 2020) and operational systems in Belgium and the Netherlands.

In April 2019, two pilot projects were launched, one in London led by the Greater London Authority and the other in north-east England led by Ordnance Survey. The projects bring together asset owners and local authority stakeholders to help understand what a national programme could look like by deploying and testing a prototype underground asset register. The aim is to identify the best approach to scaling the register to a national level, informing what data are required, how they are shared, how they can be updated, how they can be accessed and by whom.

The two pilot registers allow participating users to log in securely and view a combined map of all buried assets available at a requested site. Even at the pilot stage this includes gas and water pipes, electricity and telecoms ducts and cables, sewers, transport and local authority assets and private network assets. Users can switch layers on and off, query the attributes of assets and view cross-sectional drawings associated with points on the electricity network.

To keep the case for initial public investment clear and evidenced, the pilots are strictly focused on three use cases: safe excavation, project efficiency (planning and on site) and data-exchange efficiency. Further use cases, such as flood risk modelling and road works planning, might be included in due course, drawing on expert advice from Project Iceberg (Ordnance Survey, 2020).

The team also works closely with the Centre for Digital Built Britain (University of Cambridge, 2020), the National Infrastructure Commission (NIC, 2020) and the Energy Data Taskforce (HMG, 2020) regarding their initiatives to enable better sharing of data and models of the built environment and energy systems.

\section{Early conclusions}

The two pilot projects have so far been a collaborative success. Over 35 organisations have voluntarily shared data and knowledge, with the emerging results based on mutual trust, respect and collaboration.

Feedback to date has been overwhelmingly positive. The next steps

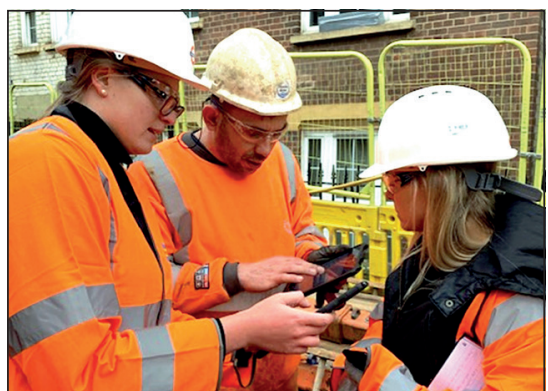

Field testing of the prototype asset data register in London is being led by the Greater London Authority with the support of J Browne Construction on behalf of Thames Water

are to take what has been learned and apply this knowledge to scaling the opportunity for others to benefit across the UK.

\section{References}

HMG (Her Majesty's Government) (2020) Energy Data Taskforce. See https://www.gov.uk/ government/groups/energy-data-taskforce accessed 28/02/2020).

Kessler H (2019) Getting under the surface of our National Underground Assets Register (NUAR). Geospatial Commission Blog, 18 December. See https://geospatialcommission.blog.gov.

uk/2019/12/18/getting-under-the-surface-of-ournational-underground-assets-register-nuar-team/ (accessed 28/02/2020).

NIC (National Infrastructure Commission) (2020) https://www.nic.org.uk/who-we-are/ (accessed 28/02/2020)

Ordnance Survey (2020) Managing Underground Assets: Project lceberg. Ordnance Survey, Southampton, UK. See https://www. ordnancesurvey.co.uk/business-government/ innovation/underground-infrastructure (accessed 28/02/2020)

SRWC (Scottish Road Works Commissioner) (2020) Vault - Access to Information on the Location of Underground Pipes and Cables. SRWC, Edinburgh, UK. See https://roadworks.scot/ legislation-guidance/further-guidance/vaultaccess-information-location-underground-pipesand-cables (accessed 28/02/2020).

University of Cambridge (2020) About the Centre for Digital Built Britain. University of Cambridge, Cambridge, UK. See https://www.cdbb.cam. ac.uk/AboutDBB (accessed 28/02/2020). 